\title{
Operational research and diagnosis for service maintenance and repair of large-loaded equipment of the company Minetech Machinery LLC official dealer of Hitachi
}

\author{
Olga Nedzelskaya ${ }^{1}$, Anna Bikineeva $^{2}$,Elena Bulakina $^{2 *}$,Vladislav Moiseev², \\ Dmitry Pochufarov ${ }^{2}$, and Alexander Ketov ${ }^{2}$ \\ ${ }^{1}$ Khakass State University, Abakan, 655017, Russia \\ ${ }^{2}$ Siberian Federal University, Krasnoyarsk, 660041, Russia
}

\begin{abstract}
The mining industry is one of the main industries that determine the country's energy sovereignty. This article studies the effectiveness of organizational and managerial decision making, a separate subdivision of Minetech Machinery LLC, an official dealer of mining equipment from Hitachi, on the territory of the Russian Federation.
\end{abstract}

\section{Introduction}

Today, with the growth of urbanization and the stable dependence of the economy on minerals, metals and coal, minerals are in the greatest demand in history. In Russia, the mining industry is one of the main industries that determine the country's energy sovereignty. The constant increase in the production of resources, in particular ore and coal, entails an increase in demand for special machinery and equipment, and the inaccessibility of deposits, difficult climatic conditions and the specifics of work, in turn, dictate special requirements for means of mechanization.

The most common types of quarry equipment used in the mining industry are various types of excavators, heavy / medium-duty dump trucks, tractors, loaders, bulldozers, graders. All of them differ in type, power, carrying capacity and technical parameters, providing a certain range of tasks to be performed, high productivity, simplification of the technological process and other advantages.

In this article, we review the activities of Minetech Machinery LLC, an official dealer of Hitachi mining equipment in the Russian Federation.

\section{Research part}

Minetech Machinery LLC (Moscow) was opened at the end of 2016 and from January 1, 2017is the only official distributor of Hitachi Construction Machinery in Russia authorized

\footnotetext{
*Corresponding author: elenagb09@mail.ru
} 
to sell mountain-class equipment, spare parts for it, as well as provide technical and service maintenance.

Figure 1 shows the model range of Hitachi equipment supplied by Minetech Machinery to Russia.

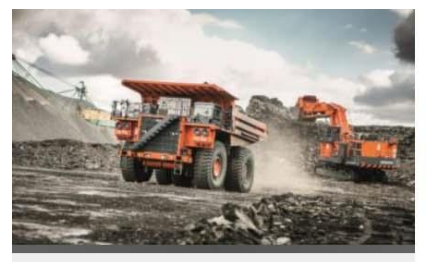

\section{EH3500}

rated engine power

(kw) ISO 9249, nct $\quad 1491 \mathrm{kw}$

maximum travel speed $(\mathrm{km} / \mathrm{h}) \quad 56 \mathrm{~km} / \mathrm{h}$

rated load capacity $(\mathrm{kg})$

$181000 \mathrm{~kg}$

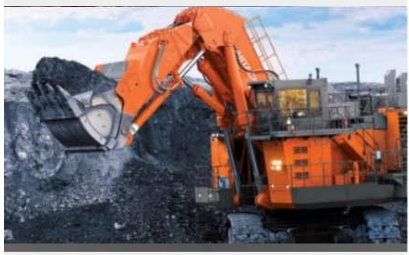

\section{EX3600-6}

Rated engine power (kw)

Operating weight $(\mathrm{kg})$

Capacity of the bucket loaded

according to ISO

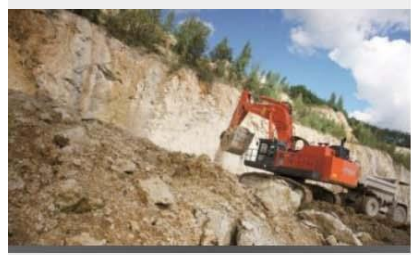

\section{EX1200-6}

Rated engine power (kw)

Operating weight $(\mathrm{kg})$

Capacity of the bucket loaded

according to ISO

$5.20-6.70 \mathrm{~m} 3$

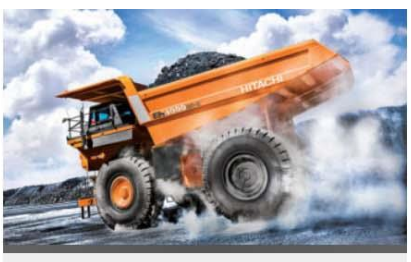

\section{EH4000}

rated eng ine power

(kw) ISO 9249, nct $\quad 1864 \mathrm{kw}$

maximum travel speed $(\mathrm{km} / \mathrm{h})$

rated load capacity $(\mathrm{kg})$

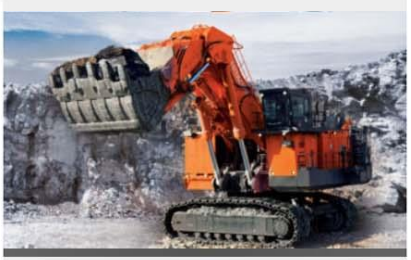

\section{EX5600-6}

Rated engine power $(\mathrm{kw})$

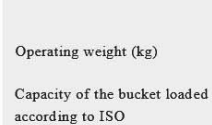

$2 \times 1119 \mathrm{kw}(2 \times 1$

$500 \mathrm{HP}$

$537000 \mathrm{~kg}$

27- $34 \mathrm{~m} 3$

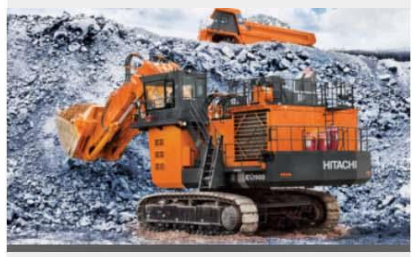

\section{EX1900-6}

Rated engine power $(\mathrm{kw})$

Operating weight (kg)

Capacity of the bucket loaded

according to ISO

Fig. 1. Model range of Hitachi equipment.

From January 2017 to May 2019, structural divisions were opened for after-sales service of heavy Hitachi machines operated throughout the Russian Federation.

The company's philosophy is to be as close to the client as possible in order to build strong partnerships together. This philosophy is based on the experience of global companies that have proven that a close relationship with a partner and understanding of a partner is the key to business success. 


\subsection{Organizational structure of the enterprise}

The organizational structure of the enterprise is shown in figure 2 .

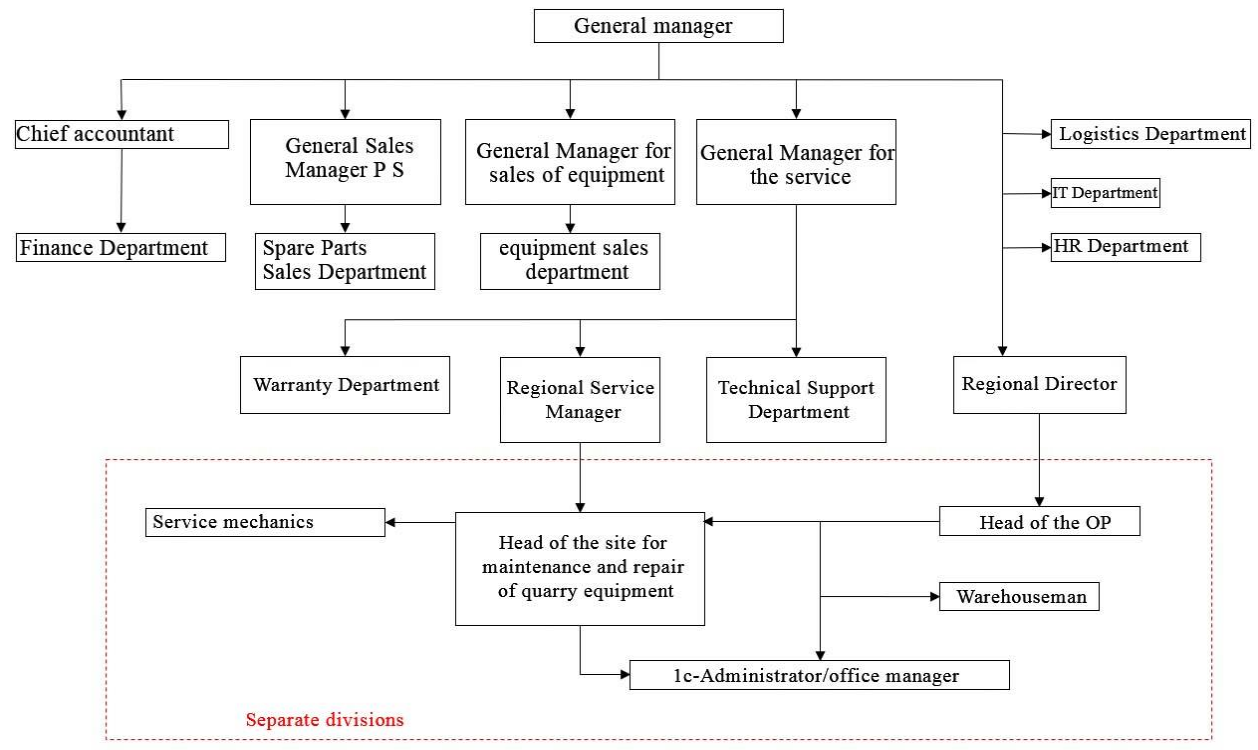

Fig. 2. Management structure.

\subsection{Characteristics of separate subdivisions}

The main task of the separate divisions is direct interaction with customers on all issues related to the acquisition and further operation of Hitachi mining equipment.

The main part of questions with customers related to the purchase of equipment and the supply of spare parts is resolved by the Head of the OP, he also decides on the functioning of a separate division.

Service mechanics by order of the head of the section for maintenance and repair of quarry equipment will carry out They conduct field visits and carry out the necessary maintenance or repair work of any complexity.

\subsection{Existing organization of maintenance and repair of personnel rolling stock}

Maintenance and repair of the company's cars is carried out at specialized service stations that are official dealers of this equipment in the region.

\subsection{Functioning of the service department}

The service department in all regions performs maintenance and repair work of any complexity of Hitachi mining equipment, with the exception of repair work for Cummins engines installed on mining excavators and rigid dump trucks, specialists from an official Cummins dealer are involved in their repair.

Applications for the performance of work from customers are received to the head of the section for maintenance and repair of quarry equipment, he instructs the $1 \mathrm{C}$ administrator to issue the planned work according to the $1 \mathrm{C}$ program and form a 
preliminary calculation or specification (depending on the terms of the service agreement), after which the head of the section for maintenance and repair of quarry equipment agrees with the customer this calculation and the timing of work on it. Within the specified timeframe, the head of the mine equipment maintenance and repair section sends service mechanics to the client's equipment to perform the necessary work. Upon completion of the necessary work, the mechanics draw up a technical act for the work performed and sign them with the authorized representatives of the customer.

If it is necessary to overhaul a unit or unit, this unit is sent to a subdivision in Novokuznetsk, where there is a workshop for overhaul of components and assemblies. There they carry out its washing, disassembly and troubleshooting, after which a defective statement and a commercial offer for its repair are drawn up. If the cost of repairing a node exceeds $75 \%$ of the cost of a new node, the client is offered to exchange the old node for a new one under the REMAN program at a cost equal to $75 \%$ of the new node.

\section{Technological enterprise equipment and tools of the OP in the city of Abakan}

At this, for the maintenance and repair of the customer's equipment, there is the necessary equipment and tooling for maximum mechanization of all processes.

The main technological equipment is a mobile workshop based on a KAMAZ 65115 vehicle, equipped with all the necessary equipment for maximum mechanization of the process. maintenance and repair of heavy excavators and dump trucks from Hitachi.

The layout of the mobile repair shop is shown in figures 3 .

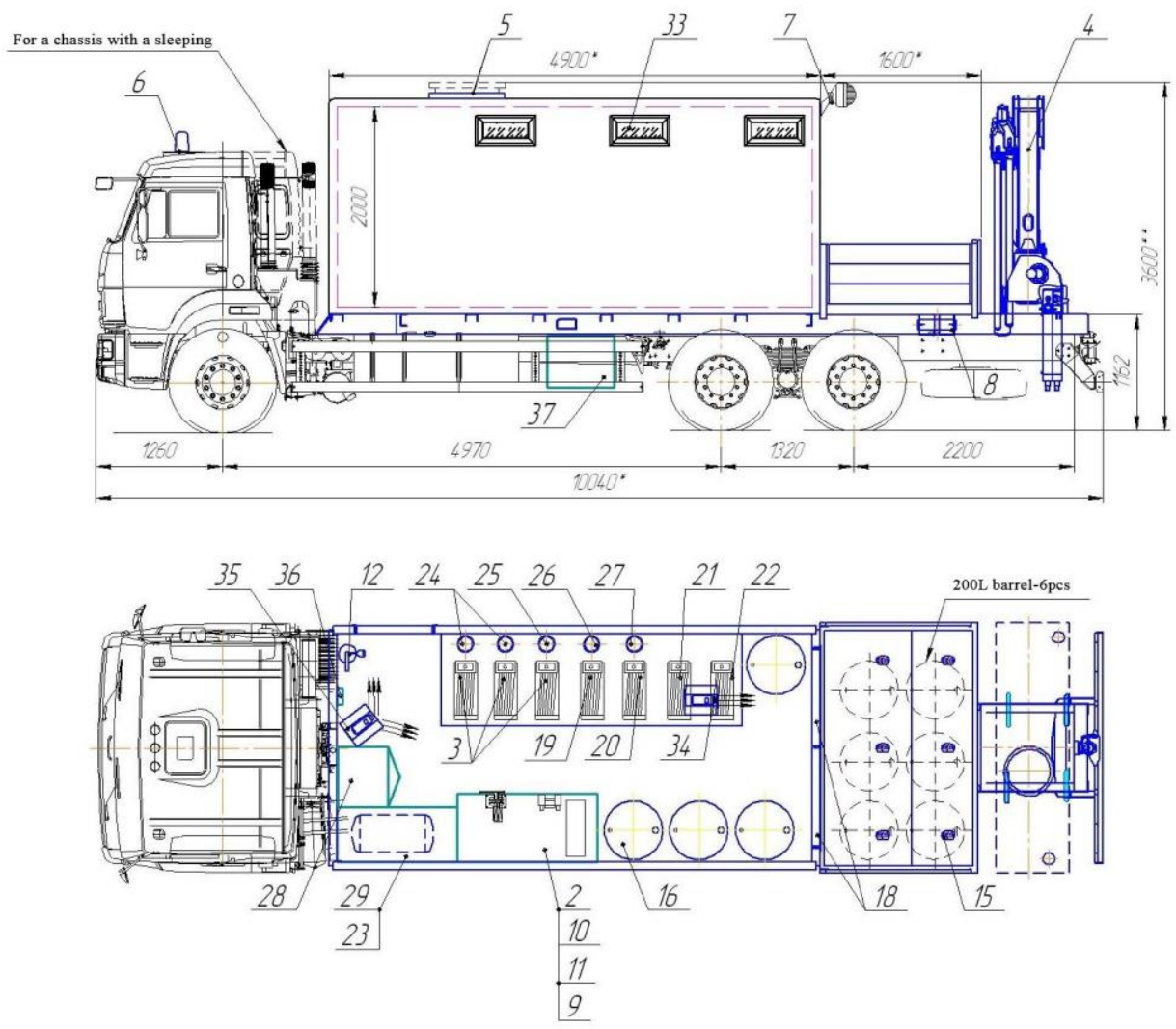




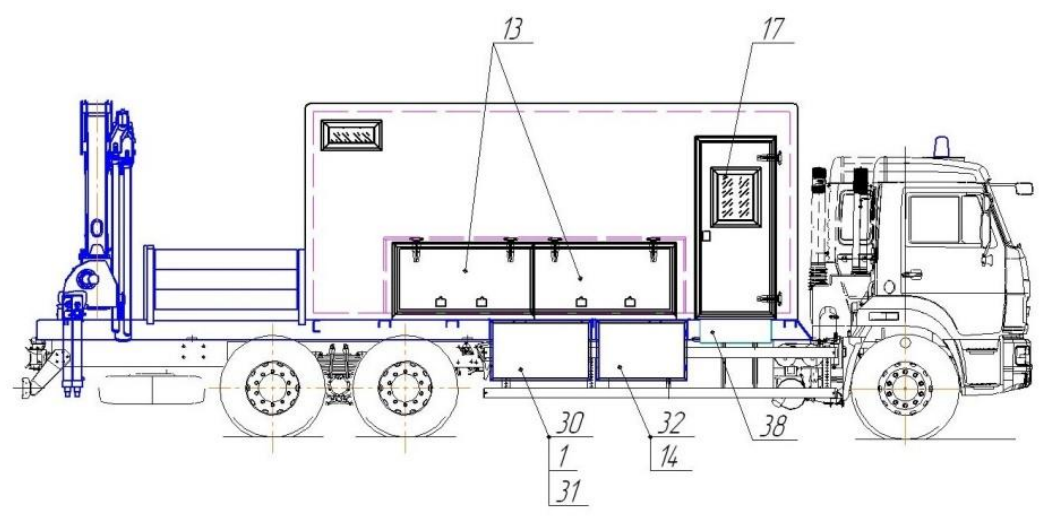

Fig. 3. Layout of a mobile repair shop: 1 - hydraulic compressor Dynaset, 2 - workbench table, type VP-3, 3 - Graco DX-30 coil, 4 - KMU SIBERIA 105A3, 5 - emergency ventilation hatch, 6 - orange beacon, 7 - search light, 8 - tool box, 9 - drilling machine, 10 - vice, 11 - grinder, 12 - fire extinguisher, 13 - hatch for access to oil dispensing coils and pneumatic tools, 14 - hydraulic generator Dynaset, 15 - load securing rings, 16 - 200 liter barrel, 17 - side door with a window, 18 rear door, 19 - Graco grease reel, 20 - Waste oil reel, 21 - Air tool reel 1/2 "connection, 22 - Air tool reel 3/4" connection, 23 - 110 liter receiver, 24 - Graco Fire-Ball 3 pump: 1, 25 - Graco Fire-Ball 3: 1 pump with filter, 26 - Graco Fire-Ball 50: 1 pump, 27 - Graco Husky pump, 28 - Workwear closet, 29 - Rack above the receiver, 30 - a box for a compressor and a radiator for cooling the hydraulic system, 31 - a fan for a hydraulic system, 32 - a box for a generator and a hydraulic distributor, 33 a window, 34 - a Webasto diesel heater $2.2 \mathrm{~kW}, 35$ - a Webasto diesel heater $5.5 \mathrm{~kW}, 36$ - first aid kit, 37 - hydraulic tank, 38 - ladder in a box.

\section{Automated reports of the ConSite system}

All heavy machines supplied from factories Hitachi since 2018, supplied with data terminals. Modification of the equipment allows partially viewing the readings of the equipment by the dealer's employees remotely, using the Globale-Service system operating on the site of the same name www.globaleservice.com.. The main advantage of this system is the formation of automated Con Site reports on the operation of equipment for each month. Part of the report is presented in figures 4,5,6. As an example, basic information on the operation of the machine for the reporting period is shown. For example, figure 4 shows the operation of the EX1900-6 excavator for March 2019, in the form of graphs of engine operation, performing a movement operation, performing an operation of rotating the rotary part, and performing working operations.

Also, all operational data can be displayed in the form of a table.

This information helps to provide the client with comprehensive assistance in resolving issues related to problems during the operation of equipment, control of fuel consumption, planning the timing of overhaul of equipment units. The efficiency of equipment operation can be monitored on the appropriate boards and deviations from the standard indicators and characteristics can be recorded.

Based on the research carried out and the fixed data on the operating time of the Hitachi EX1200-6 excavator, in March, it completed 450 hours of 608 hours of total engine operation, the operating efficiency is approximately $75 \%$, it follows that it did not perform any operations. The total downtime of equipment for the entire period of operation of the machine was 4045 hours out of 11003 hours, which is approximately $36 \%$ of the total operating time of the engine of the equipment.

Preventive maintenance of the Hitachi EX1900-6 excavator. 
Consite

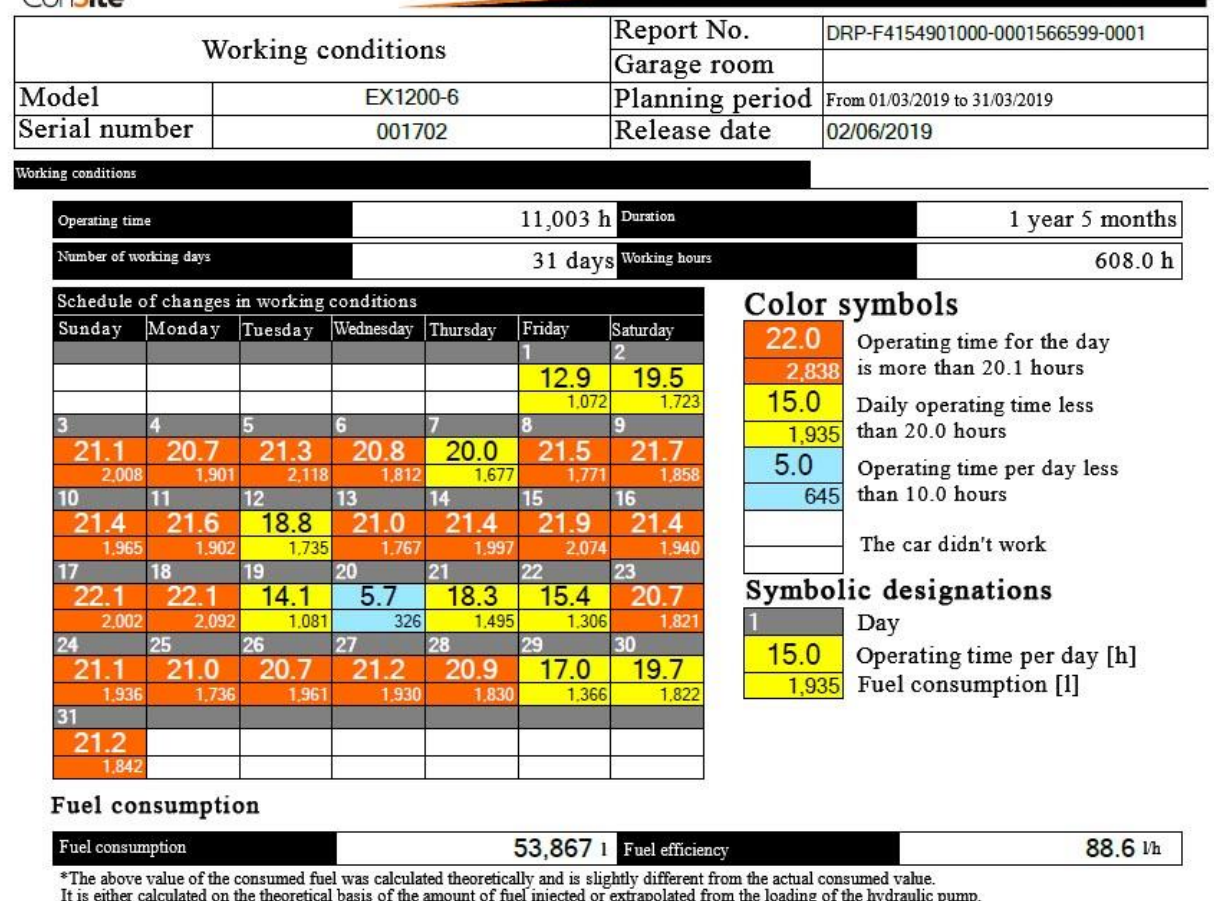

\section{Daily working hours}

- Operating time of the machine

- Non-working hours

$\rightarrow$ Fuel consumption

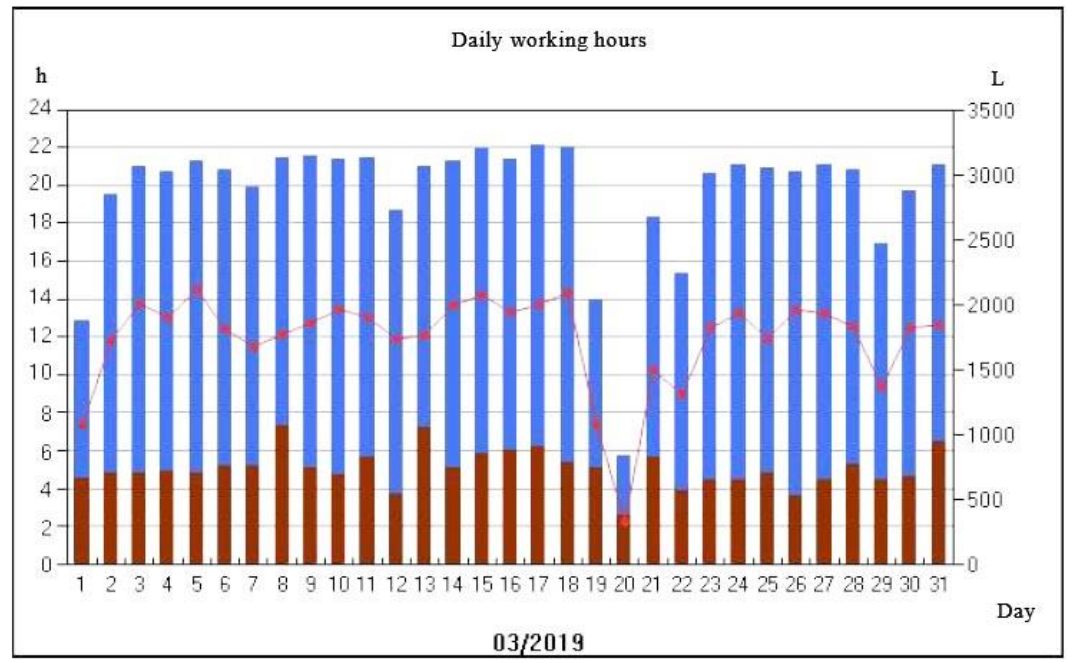

* $\square$ The operating conditions cannot be displayed because not enough data has been received from the machine

Fig. 4. ConSite automated report element. 


\section{Consite}

\begin{tabular}{|l|c|l|l|}
\hline \multicolumn{2}{|c|}{ Working conditions } & Report No. & DRP-F4154901000-0001566599-0001 \\
\cline { 3 - 4 } & Garage room & \\
\hline Model & EX1200-6 & Planning period & From 01/03/2019 to 31/03/2019 \\
\hline Serial number & 001702 & Release date & $02 / 06 / 2019$ \\
\hline
\end{tabular}

Working hours (details)

Working hours

\begin{tabular}{|c|c|c|c|c|c|c|}
\hline Position & Current month & 130 & 260 & 390 & 520 & 650 \\
\hline Engine operating time & $608.0 \mathrm{~h}$ & & & & & \\
\hline Non-working hours & $157.3 \mathrm{~h}$ & tat & & & & \\
\hline Move operation & $54.0 \mathrm{~h}$ & E & & & & \\
\hline Rotation operation & $292.2 \mathrm{~h}$ & & & & & \\
\hline Operating time of the machine & $450.7 \mathrm{~h}$ & & & & & \\
\hline
\end{tabular}

Since the combined operation execution time is added to each corresponding working time, the total working time may exceed. Engine operating time

\section{Total working time}

\begin{tabular}{|c|c|c|c|c|c|c|c|}
\hline Position & Total & 0 & 2210 & 4420 & 6630 & 8840 & 11050 \\
\hline Engine operating time & $11,003.2 \mathrm{~h}$ & & & & & & \\
\hline Non-working hours & $4,045.7 \mathrm{~h}$ & & & & & & \\
\hline Move operation & $494.2 \mathrm{~h}$ & E & & & & & \\
\hline Rotation operation & $4,379.1 \mathrm{~h}$ & & & & & & \\
\hline Operating time of the machine & $6,957.5 \mathrm{~h}$ & & & & & & \\
\hline
\end{tabular}

Since the combined operation execution time is added to each corresponding working time, the total working time may exceed. Engine operating time

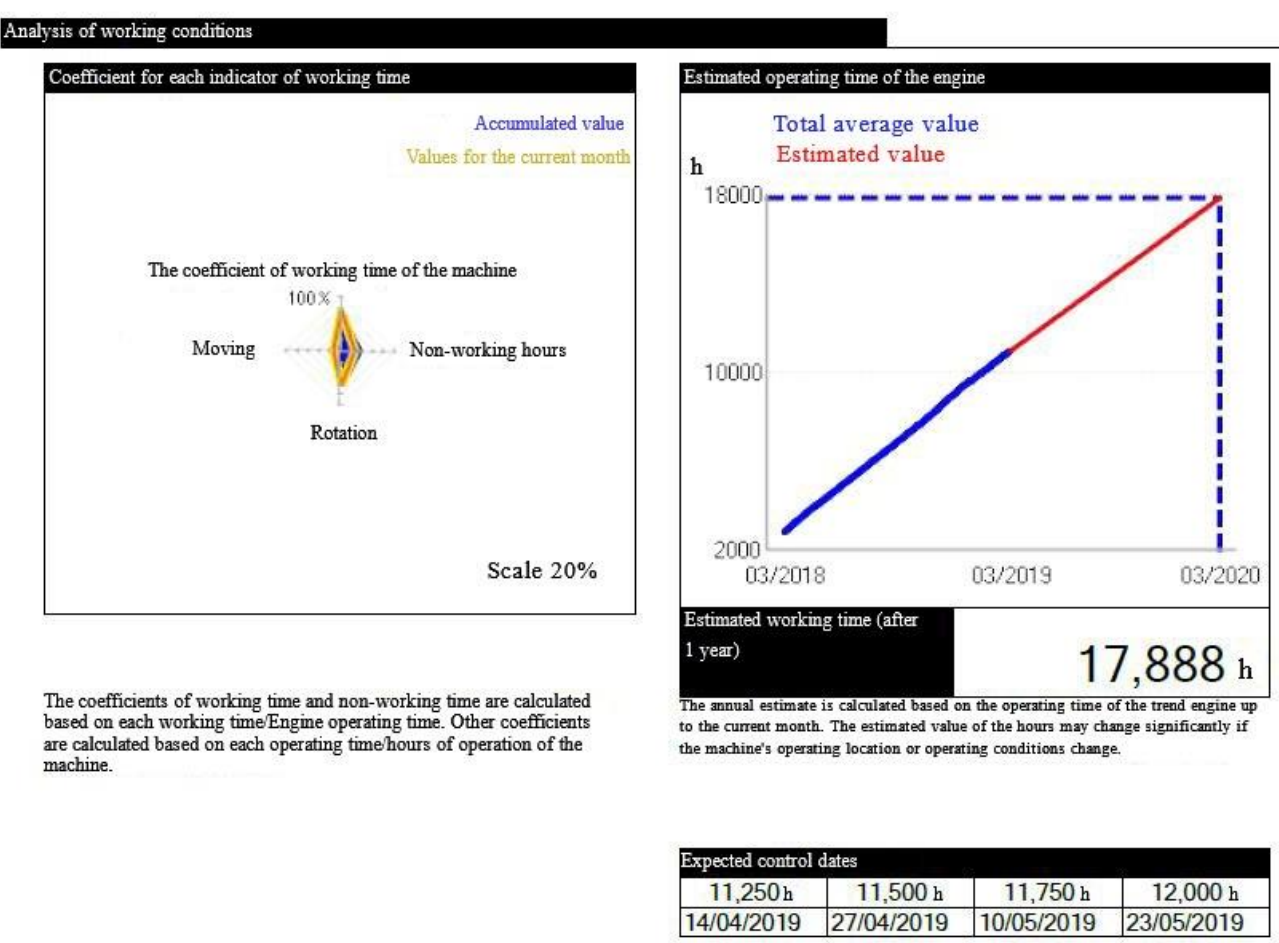

Fig. 5. ConSite automated report element. 


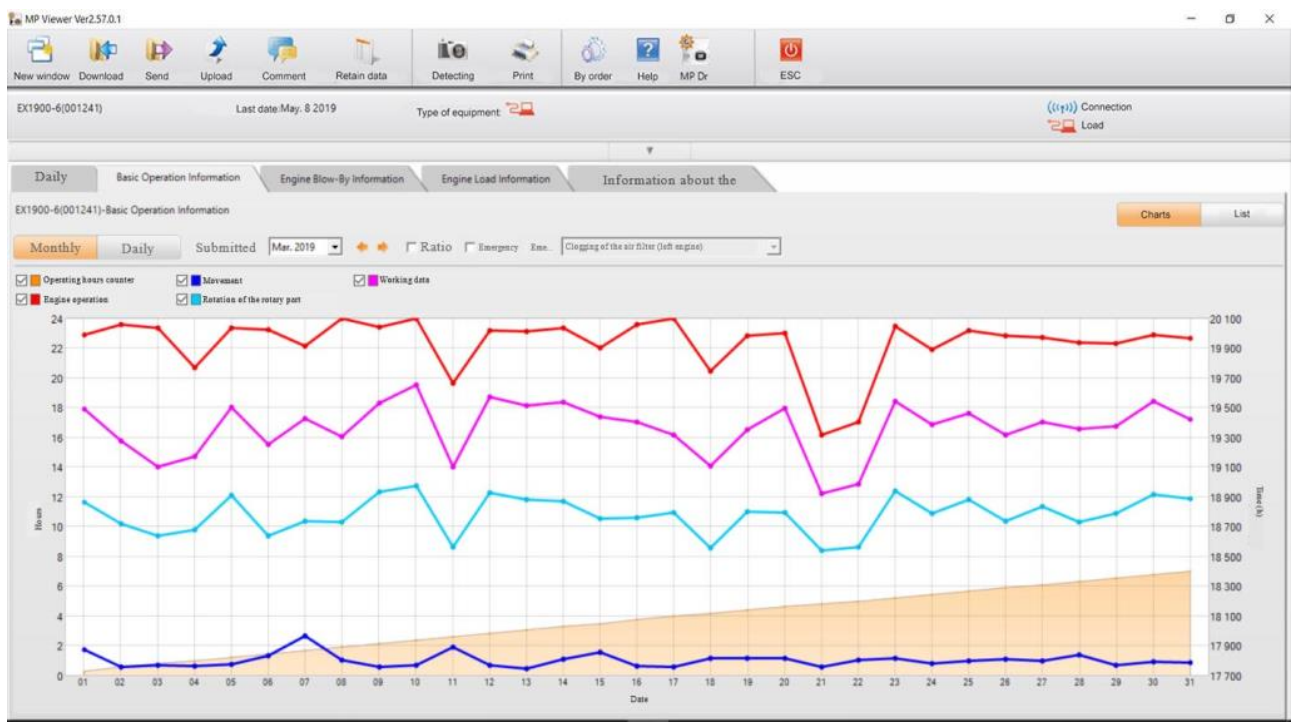

Fig. 6. Basic information on the operation of equipment.

As an example, in April, at a separate subdivision of Minetek Machinery LLC in Abakan, it was planned to carry out preventive maintenance of the Hitachi EX1900-6 mining excavator with operating time of 48,000 motorcycle hours, at the client of JSC MC Stepnoy Razrez.

To carry out scheduled preventive maintenance, a list of spare parts needed was agreed with the client. The client purchased all the necessary spare parts and assemblies.

Necessary components and assemblies for routine maintenance: slewing bearing $-1 \mathrm{pc}$., QSKTA-38 engine - 1 pc., Main hydraulic pumps - 3 pcs., Auxiliary hydraulic pumps - 2 pcs., Swing mechanism -1 pc. ., travel hydraulic motors -2 pcs., a set of electrical wiring elements -1 pc., a fan drive hydraulic motor -1 pc., a central hinge -1 pc., a track tensioner -2 pcs., a boom lifting cylinder -2 pcs., a handle hydraulic cylinder -2 pcs. , bucket hydraulic cylinder -2 pcs., hydraulic radiator -2 pcs., engine cooling radiator element -4 pcs., pump drive reducer repair kit (bearings, gears, seals) -1 pc., as well as spare parts necessary for the installation of these components (o-rings, gaskets, etc.).

\section{References}

1. E.N. Bulakina, O.N. Nedzelskaya, et al., IOP. Conf. Ser.: MSE, 411 (2018)

2. E.N. Bulakina, O.N. Nedzelskaya, et al., IOP Conf. Ser.: EES, 377 (2019)

3. E.N. Bulakina, O.N. Nedzelskaya, D.O. Pochufarov, IOP Conf. Ser.: MSE, 168 (2019)

4. O.N. Nedzelskaya, V.V. Moiseev, et al., IOP Conf. Ser.: MSE, 865 (2020)

5. A.N. Bikineeva, O.N. Nedzelskaya, et al., IOP Conf. Ser.: MSE, 454 (2019) 